\title{
Three interpretations of the association between birth weight and cardiovascular disease
}

\author{
Per Magnus \\ Department of Genes and Environment, Division of Epidemiology, Norwegian Institute of Public Health, Oslo, Norway \\ Correspondence: Per Magnus, Norwegian Institute of Public Health, P.O. Box 4404, 0403 Oslo, Norway \\ Telephone: +4723408211 Telefax: +4723408252 e-mail: per.magnus@fhi.no
}

\begin{abstract}
SUMMARY
Most epidemiological studies of cardiovascular disease have had a focus on smoking, blood pressure, diet, physical activity and obesity in adulthood as determinants of cardiovascular disease. A few studies from the 1970s and onwards attempted to shed light on the early origins of this disease, and it is now established through cohort studies that there is a fairly strong and consistent relationship between low birth weight and increased risk of later cardiovascular disease. However, the interpretation of this relationship is under discussion. Three alternative interpretations of the association are discussed. The first interpretation, the environmental causal model, claims that the external influences on the growth of fetal organ systems have detrimental biological consequences that predispose the child for cardiovascular disease as an adult. This is the fetal programming hypothesis, which presently more often is called the theory of developmental plasticity, integrating environmental events before and after birth. The second interpretation, the genetic confounding model, says that the association between low birth weight and later cardiovascular disease is not causal. The association is due to confounding by pleiotropic genes, i.e. genes that influence more than one phenotype. The third interpretation, the environmental confounding model, says that lifestyles and general socioeconomic conditions that correlate across generations cause both low birth weight and predisposes for cardiovascular disease, and thereby leads to a spurious association. The conclusion is that, with the studies reported up to now, one cannot dismiss any of these interpretations. By utilizing the large pregnancy cohorts set up in Norway and other countries, these models can be put to critical tests.
\end{abstract}

\section{THE DATA}

\section{Ecological studies}

The story about the association between birth weight and later cardiovascular disease does not start with studies of birth weight. It begins with Anders Forsdahl's comparison of cardiovascular mortality in different areas of Norway with the infant mortality in the same areas decades before. He found that the areas, for instance Finnmark county, with increased infant mortality rates in the beginning of the last century, later had higher rates of cardiovascular mortality. Using all counties, Forsdahl described a striking correlation between infant mortality in 1896-1925 and mortality rates in the years 1964-67, as shown in figure 5.1 in Bakketeig et al. (1).

In what could also be called an ecological study, Jan Marcus Sverre used the whole population of Norway to understand the secular trends in coronary heart disease mortality in Norway from 1966 to 1986 (2). Birth weights were not available for the population under study. However, by including year of birth, period of death and age at death, it was shown by Poisson regression methods that subjects born around 1900 had particularly high risks of death from cardiovascular disease compared to subjects born in other time periods. This analysis suggests that people born in this time period had specific risk-increasing experiences, although it does not tell us at what age the experiences occurred.

In 1986, Barker and Osmond (3) reported data from 212 local authority areas in England and Wales, and could demonstrate a strong positive correlation between infant mortality (both neonatal and postneonatal) in 1921-25 and ischemic heart disease mortality rates in 1968-78 across these areas, confirming Forsdahl's observations.

\section{Historical cohorts}

A historical cohort is a study where the investigator analyses data in a prospective manner but uses old data usually not collected for research purposes, in contrast to other cohort studies where the investigator plans and collects exposure data from the start of the observation period. Birth weight is one of the variables that often can be extracted from old records. A good example of a historical cohort is provided by the Herefordshire cohort. In that area in England, a Health Visitor's Register was available with information on 71201 live births with information on birth weight and weight at one year of age for most of the children (4). Barker traced 16000 children born between 1911 and 1930, and reported that the death rate from coronary heart disease was almost twice as high for children who had been at the lower end of the birth weight scale (less than $2.5 \mathrm{~kg}$ ) compared to children above $4 \mathrm{~kg}$ at birth 
(5). Children with low weight at one year of age was about 3 times as likely to die from cardiovascular disease compared to the heaviest children (5).

Another historical cohort has been based on 14611 births that took place in Uppsala Academic Hospital in 1915-29 (6). Birth records were found for $96 \%$ of the births, and the cohort was followed from 1958 to 1995 with respect to mortality. The rate ratio for ischemic heart disease was 0.77 (95\% CI: 0.67-0.90) in men and $0.83(0.62-1.10)$ in women per 1000 gram increase in birth weight. In Helsinki, 4630 men born at the University Central Hospital in 1934-44, for whom birth records were available, were followed for hospital admissions and deaths in the period 1971-97 (7). The hazard ratio for coronary heart disease was 3.6 for men below 2500 grams at birth compared to men with birth weights above $4000 \mathrm{~g}$.

\section{Other cohort studies}

Cohort studies set up for research purposes may start when subjects are in utero (pregnancy cohorts), right after they are born (birth cohorts) or at any other age. Many cohort studies that recruit subjects as adults, try to include exposure information from earlier time periods. Thus, one may ask a participant whether he or she can report his or her birth weight or the education or occupation of the parents. This type of information is usually inaccurate. Sometimes the information can be obtained from registries or hospital records. In the Caerphilly cohort, men aged 45-59 years were recruited in 1979-83 and asked to provide data on their own birth weight based on information from their mothers or other relatives. Data were found for 1258 men who have been followed for incident coronary heart disease. The incidence of disease was twice as high for men in the lowest tertile of birth weight compared to the highest, but this relationship was only found for men with high adult body mass index (BMI) (8). A similar pattern is reported from the Nurses' Health Study (9), where 66111 female nurses have been followed since 1976. They indicated their birth weight in categories in a questionnaire in 1992, and have been followed for incident cardiovascular disease up to 2000. By dividing birth weight in 4 categories and adult BMI in 4 categories, they examined 16 groups, and found the highest risk of cardiovascular disease in the category with lowest birth weight and highest BMI.

\section{THE INTERPRETATIONS}

\section{Interpretation 1 - The environmental causal model}

This model (Figure 1) suggests that the association between birth weight and later disease is causal in the sense that birth weight is closely linked to the causal chain. It is not birth weight in itself that causes later disease, but the observed low birth weight is a reflection of the fetal growth restriction that results from environmental factors operating in utero. These environmental factors also increase the risk of perinatal death. Forsdahl suggested that it was the combination of poverty in early life and later affluence that had detrimental consequences (10). The cohort studies referred to above $(8,9)$ are in accordance with this proposition. From a physiological point of view the causal chain makes sense if one assumes that early under-nutrition will program cells to express genes that increase the uptake of fats and other nutrients from the circulation. This has been called the thrifty phenotype (11), and can be viewed as an environmental induction or adaptation to harsh surroundings (12). When affluence sets in, the uptake becomes too high and results in vascular disease. This reasoning has also been applied to explain the high incidence of cardiovascular disease and type 2 diabetes in subjects born in Asia who move to Europe in adolescence or adulthood, and can also be used to explain the epidemic of cardiovascular disease in the middle parts of the last century in Norway. Subjects born 1850-1880 were poor in both childhood and adulthood and had relatively low rates of cardiovascular disease according to Sverre's analysis (2). Relatively lower rates were also inferred for subjects born 1910-30 who lived under

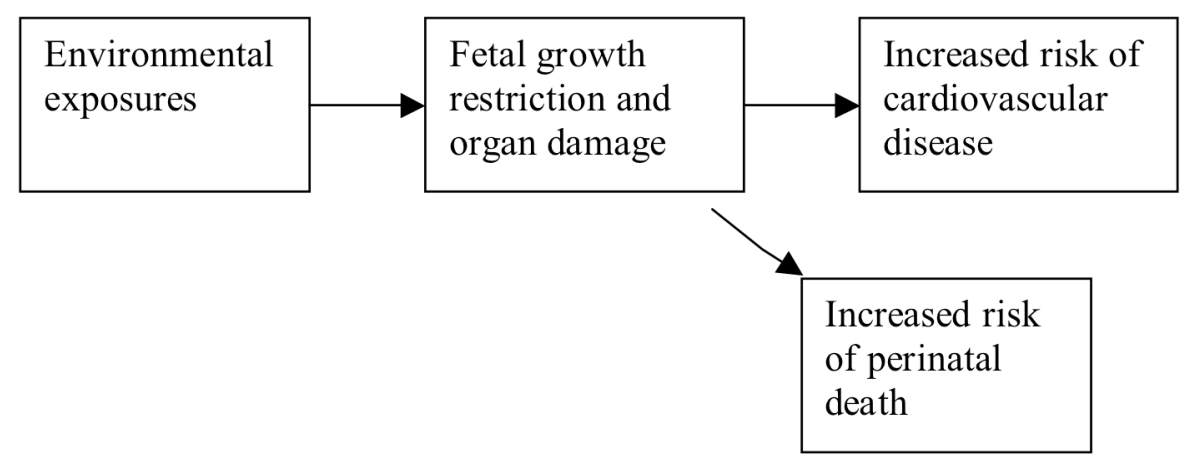

Figure 1. The environmental causal model shows how exposures, for instance those related to poverty, have effects on the growing fetus, later leading to adult disease. 
better living conditions, while subjects born 18801910 to a larger extent combined early poverty with later affluence and had the highest mortality rates. This is a very speculative, but interesting, explanation of the epidemic of coronary heart disease in Norway in the twentieth century.

When Barker made his first observations, he called this causal model the fetal programming hypothesis. He suggested that lack of nutrients and oxygen, even in short periods, will lead to reduced rates of cell division that permanently changes or programmes the structure and function of the body (5). More recently, with reference to many examples from other organisms, the concept of developmental plasticity has been used to understand the early origins of adult health (13). Gluckman et al. (14) differentiates between environmental effects that are adaptive from the ones which are disruptive, indicating more permanent and damaging changes. They suggest that there is a period of plasticity during fetal life extending to some point in time after birth. Increased risk results from a mismatch between the environment predicted during the plastic phase of development and the actual environment experienced in the post-plastic phase.

\section{Interpretation 2 - The genetic confounding model}

The genetic confounder hypothesis suggests that the environment really plays no role in the association between birth weight and later disease (Figure 2). This has been suggested by Hattersley and Tooke (15) to explain the association between birth weight and later risk of type 2 diabetes. They point out that fetal insulin secretion is one of the key determinants of fetal growth, and that this secretion is influenced by fetal genes, one of them being the gene that codes for the glycolytic enzyme glucokinase (16). To explain the association to cardiovascular disease, Hattersley and Tooke suggest that a number of fetal polygenes are pleiotropic; they influence more than one trait. One example is genes that affect insulin resistance. These genes may result in two phenotypes, one is a small, thin baby and the other is an adult with insulin resistance and increased risk of hypertension and athero- sclerosis as well as type 2 diabetes, especially in the presence of obesity.

For Model 2 to be valid, one must present evidence that genes are causing substantial variability, both in birth weight and in the liability to cardiovascular disease. For birth weight, the effects of environmental factors appear to be surprisingly small, as summarised by Leon (17). He points out that there has hardly been any increase in mean birth weight over the past hundred years, that interventions to increase birth weight by nutritional supplementation have had little effect, and that the differences in birth weight between socioeconomic groups are relatively small, as is also found in Norway (18). On the other hand, there is strong evidence that the fetal genotype explains a large part of the variance in birth weight, both when using an analysis of latent factors on the covariance structure for birth weight for sibs, maternal and paternal half-sibs and cousins $(19,20)$, and for parents and offspring (21). Both twin studies and family studies are compatible with a significant genetic influence on the risk of cardiovascular disease, as summarized by Stephens and Humphries (22).

In considering the genetic confounder hypothesis, it is interesting to review Forsdahl's observations in two ethnic groups in Finnmark. He showed that the risk of cardiovascular death was higher in men and women of Finnish ethnic origin in one municipality (Sør-Varanger) that he studied intensively, than in men and women of Norwegian ethnic origin. For instance among men in the age range 30-79, who died in SørVaranger in the period 1964-68, the death rates were 47 per 10000 for Finnish men and 26 for Norwegian men, while the similar rates were 29.1 for the whole of Finnmark county and 23.4 for Norway (23). The infant mortality rate in Finnmark in the period 1900-1920 varied between 140 and 180 per 10000 live births (with Sør-Varanger being among the highest), whereas for Norway as a whole it was between 50 and 70 (23). When estimating ecological associations, the estimates should be performed within strata of the same ethnic origin. However, this lack of confounder control is not likely to explain Forsdahl's or Barker's observations.

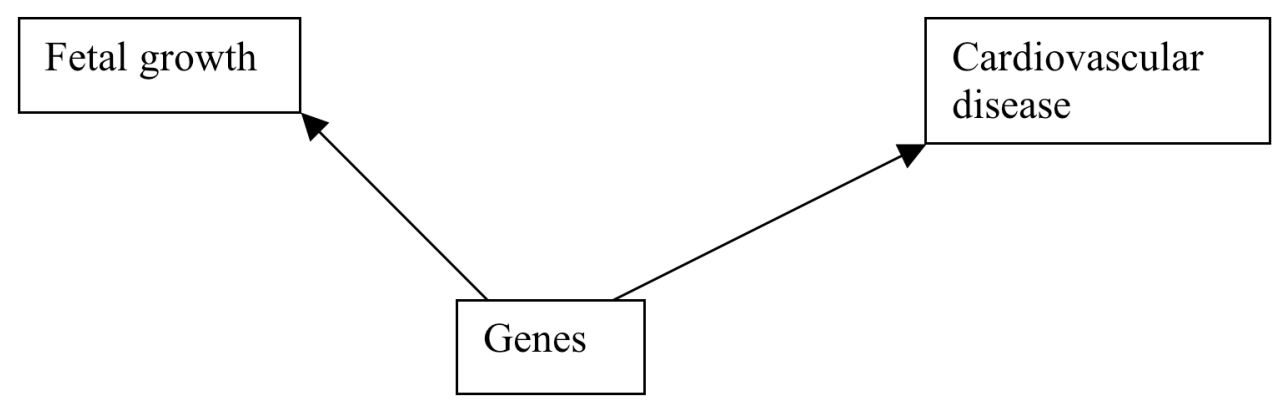

Figure 2. The genetic confounder interpretation says that the association between birth weight and cardiovascular disease is completely caused by genes that influence fetal growth and later also contribute to the risk of cardiovascular disease. 


\section{Interpretation 3 - The environmental confounding} model

The environmental confounding model (Figure 3) suggests that there are underlying environmental factors that explain both the infant phenotype and the later adult phenotype. Figure 3 uses smoking as an example, since this the most common life style that is known to influence both birth weight and cardiovascular disease. Barker argues that although adult lifestyle may add to intrauterine effects, the association is not explained by adult exposures and lifestyles, and points to studies that show that the intrauterine effect is present independently of smoking and obesity in later life (5). The Swedish study and the Nurses' Health Study (9) are the cohorts with best confounder control as yet, but there is still inadequate control for lifestyles and socioeconomic factors at the time of birth, and rest-confounding should be considered as an explanation of the association. Both Lawlor et al. (24) and Kramer (25) discuss confounding, but whereas the former tends to dismiss confounding as an unlikely explanation, the latter author points both to socioeconomic factors and to maternal disease as an explanation. For instance if reduced fetal growth is a consequence of maternal hypertension and offspring hypertension is causally related to the factors (whether these are genetic or environmental) that led to the maternal hypertension, then the fetal growth restriction is merely a side issue. In the light of this proposition, it is interesting to note that Davey Smith et al. report increased mortality for mothers with low birth weight offspring (26).

Twins have been suggested as a natural experiment to test the fetal programming hypothesis, as twins weigh on average $900 \mathrm{~g}$ less than singletons at birth, and one would therefore expect twins as a group to have increased rates of death from cardiovascular diseases. Both a Swedish and a Danish follow-up of twins from the national registries have, however, failed to demonstrate any difference between twins and singletons in mortality $(27,28)$. However, the reduced birth weight in twins is of another nature (crowding, shorter gestational length) than the reduction in singletons, and it is doubtful whether any conclusions about the fetal origin of adult disease can be drawn from the twin studies.

\section{CONCLUSION AND FURTHER RESEARCH}

The models have very different implications for public health, and it is important to carry out research than can critically test the hypotheses. Until now, it is mostly a matter of intuition which theory to adhere to. The fetal programming hypothesis has been supported by animal experiments, which has not been reviewed here, but it is still a leap of faith to say that this hypothesis (model 1) is more likely to be true than for instance the genetic confounder hypothesis (model 2). In the end, all three interpretations may turn out to be relevant to some degree. The epidemiological observations, starting with Forsdahl's study, have led to a lot of speculation about socioeconomic and biological mechanisms, which has stimulated research during the past 20 years. The possible fetal influence on adult disease stimulated the planning of the Norwegian Mother and Child Cohort Study (29). One of the reasons that there is such a controversy between scientists in this area is the lack of data from large pregnancy cohorts that include biological material collected during the fetal period. There is a long time before results on adult disease will be available from these cohorts (29-31), but early markers of disease will soon be analysed. Clearly, the models discussed in this paper cannot be validly tested unless one has individual data with sufficient detail on early and late exposures as well as potential confounders from before birth to adult age (32).

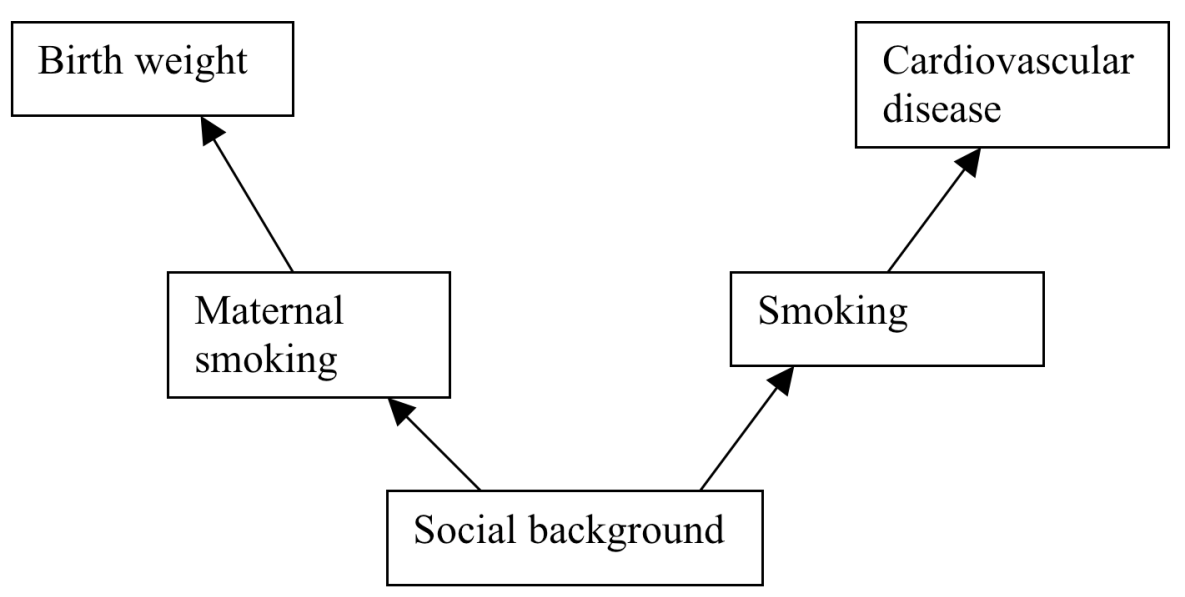

Figure 3. The environmental confounder model suggests that the same background factors can influence both early and late phenotypes, in this figure exemplified by smoking. 


\section{REFERENCES}

1. Bakketeig LS, Magnus P, Sundet JM. Differential development of health in a life-span perspective. In: Magnusson D, Bergman LR, Rudinger G, Tørestad B, eds. Problems and methods in longitudinal research: Stability and change. Cambridge: Cambridge University Press, 1991: 95-106.

2. Sverre JM. Secular trends in coronary heart disease mortality in Norway, 1966-1986. Am J Epidemiol 1993; 137: 301-10.

3. Barker DJ, Osmond C. Infant mortality, childhood nutrition, and ischaemic heart disease in England and Wales. Lancet 1986; i: 1077-81.

4. Razzell P, Spence C, Vines K. Poverty, birthweight, and infant weight gain in Hertfordshire, 1923-39. Int J Epidemiol 2004; 33: 1228-33.

5. Barker DJP. Fetal nutrition and cardiovascular disease in later life. Brit Med Bull 1997; 53: 96-108.

6. Leon DA, Lithell HO, Vågerø D, Koupilova I, Mohsen R, Berglund L, et al. Reduced fetal growth rate and increased risk of death from ischemic heart disease: cohort study of 15000 Swedish men and women born 1915-29. BMJ 1998; 317: 241-5.

7. Eriksson JG, Forsen T, Tuomilehto J, Osmond C, Barker DJP. Early growth and coronary heart disease in later life: longitudinal study. BMJ 2001; 322: 949-53.

8. Frankel S, Elwood P, Sweetnam P, Yarnell J, Smith GD. Birthweight, body-mass index in middle age, and incident coronary heart disease. Lancet 1996; 348: 1478-80.

9. Rich-Edwards JW, Kleinman K, Michels KB, Stampfer MJ, Manson JE, Rexrode KM, et al. Longitudinal study of birth weight and adult body mass index in predicting risk of coronary heart disease and stroke in women. BMJ 2005; 330: 1115-20.

10. Forsdahl A. Are poor living conditions in childhood and adolescence an important risk factor for arteriosclerotic heart disease? Br J Prev Soc Med 1977; 31: 91-5.

11. Hales CN, Barker DJP. Type 2 (non-insulin-dependent) diabetes mellitus: the thrifty phenotype. Diabetologia 1992; 35: 595-601.

12. Bateson P. Fetal experience and good adult design. Int J Epidemiol 2001; 30: 928-34.

13. Bateson P, Barner D, Clutton-Brock T, Deb D, D'Udine B, Foley RA, et al. Developmental plasticity and human health. Nature 2004; 430: 419-21.

14. Gluckman PD, Cutfield W, Hofman P, Hanson MA. The fetal, neonatal, and infant environments - the longterm consequences for disease risk. Early Hum Develop 2005; 81: 51-9.

15. Hattersley AT, Tooke JE. The fetal insulin hypothesis: an alternative explanation of the association of low birth weight with diabetes and vascular disease. Lancet 1999; 353: 1978-92.

16. Hattersley AT, Beards F, Ballantyne E, Appleton M, Harvey R, Ellard S. Mutations in the glucokinase gene of the fetus result in reduced birth weight. Nat Genet 1998; 19: 268-70.

17. Leon DA. Biological theories, evidence, and epidemiology. Int J Epidemiol 2004; 33: 1167-71.

18. Arntzen A, Samuelsen SO, Magnus P, Bakketeig LS. Birth weight related to social indicators in Norway. Eur J Publ Health 1994; 4: 92-7.

19. Magnus P. Causes of variation in birth weight: A study of offspring of twins. Clin Genet 1984; 25: 15-24.

20. Magnus P. Further evidence for a significant effect of fetal genes on variation in birth weight. Clin Genet 1984; 26: 289-96.

21. Magnus P, Gjessing HK, Skrondal A, Skjærven R. Paternal contribution to birth weight. J Epidemiol Community Health 2001; 55: 873-7.

22. Stephens JW, Humphries SE. The molecular genetics of cardiovascular disease: clinical implications. $J$ Intern Med 2003; 253: 120-7.

23. Forsdahl A. Observations throwing light on the high mortality in the county of Finnmark. Is the high mortality today a late effect of very poor living conditions in childhood and adolescence? Int J Epidemiol 2002; 31: 302-8.

24. Lawlor DA, Ben-Schlomo Y, Leon DA. Pre-adult influences on cardiovascular disease. In: Kuh D, BenShlomo Y, eds. A life course approach to chronic disease epidemiology. Oxford: Oxford University Press, 2004, 41-76.

25. Kramer MS. Association between restricted fetal growth and adult chronoc disease: Is it causal? Is it important? Am J Epidemiol 2000; 152: 605-8.

26. Davey Smith G, Hart C, Ferrell C, Upton M, Hole D, Hawthorne V, Watt G. Birth weight of offspring and mortality in the Renfrew and Paisley study: prospective observational study. BMJ 1997; 315: 1189-93.

27. Vågerø D, Leon D. Ischemic heart disease and low birth weight: a test of the fetal-origins hypothesis from the Swedish Twin Registry. Lancet 1994; 343: 260-3.

28. Christensen K, Vaupel JW, Holm NV. Mortality among twins after age 6: fetal origins versus twin method. $B M J$ 1995; 310: $432-6$. 
29. Magnus P, Irgens LM and the Norwegian Mother and Child Cohort Study Group. Searching for early causes of disease. The aims, methods, participation and follow-up rates of the Norwegian Mother and Child Cohort Study. Submitted for publication.

30. Golding J, Pembrey M, Jones R and the ALSPAC study team. ALSPAC - The Avon longitudinal study of parents and children. I. Study methodology. Paediatr Perinatal Epidemiol 2001; 15: 74-87.

31. Olsen J, Melbye M, Olsen SF, Sørensen TIA, Aaby P, Andersen AMN, et al. The Danish National Birth Cohort - its background, structure and aim. Scand J Publ Health 2001; 29: 300-7.

32. Susser E, Terry MB, Matte T. The birth cohorts grow up: new opportunities for epidemiology. Paediatr Perinatal Epidemiol 2000; 14: 98-100. 